\title{
Welfare impacts of climate change
}

Climate change can affect well-being in poor economies more than previously shown if its effect on economic growth, and not only on current production, is considered. But this result does not necessarily suggest greater mitigation efforts are required.

\section{Andries F. Hof}

$$
\text { T }
$$
he impacts of climate change include, but are not limited to, increased heat stress, land loss due to sea level rise, and changes in agricultural productivity with consequences for the welfare of populations across the world. As the major cause of climate change is $\mathrm{CO}_{2}$ emissions, the value of the total welfare impact of the change in climate caused by one extra ton of $\mathrm{CO}_{2}$ emissions can be estimated and is known as the social cost of carbon (SCC). The SCC is of great importance for policymakers, as it provides guidance on how to value the benefits of $\mathrm{CO}_{2}$ reductions. The US government, for instance, provides SCC estimates to allow agencies to incorporate the value of the benefits of reducing $\mathrm{CO}_{2}$ emissions in the evaluation of regulatory actions ${ }^{1}$. Currently, SCC estimates are based on the assumption that climate change affects economic output - the amount of goods and services produced at present - but not the rate at which an economy grows over time. Although the difference may sound trivial, writing in Nature Climate Change, Frances Moore and Delavane Diaz ${ }^{2}$ show that considering a direct effect of climate change on economic growth would lead to an estimate of the SCC that could be several times larger than previously thought.

Most estimates of the SCC are based on economic integrated assessment models (IAMs). There are many types of IAM, but all of them aim at studying the most relevant interactions between the human system and the earth system. Economic IAMs are characterized by a simple representation of the earth system, such as the climate system and the physical consequences of climate change, and a more complex representation of the economy. Although economic IAMs have been subject to criticism, especially because the assumed relationship between global warming and loss of economic output - as depicted by the damage function - is based mainly on guesswork ${ }^{3,4}$, they remain influential in policy-making because of their SCC projections.

Given their large impacts on policy, the robustness of SCC projections is of great

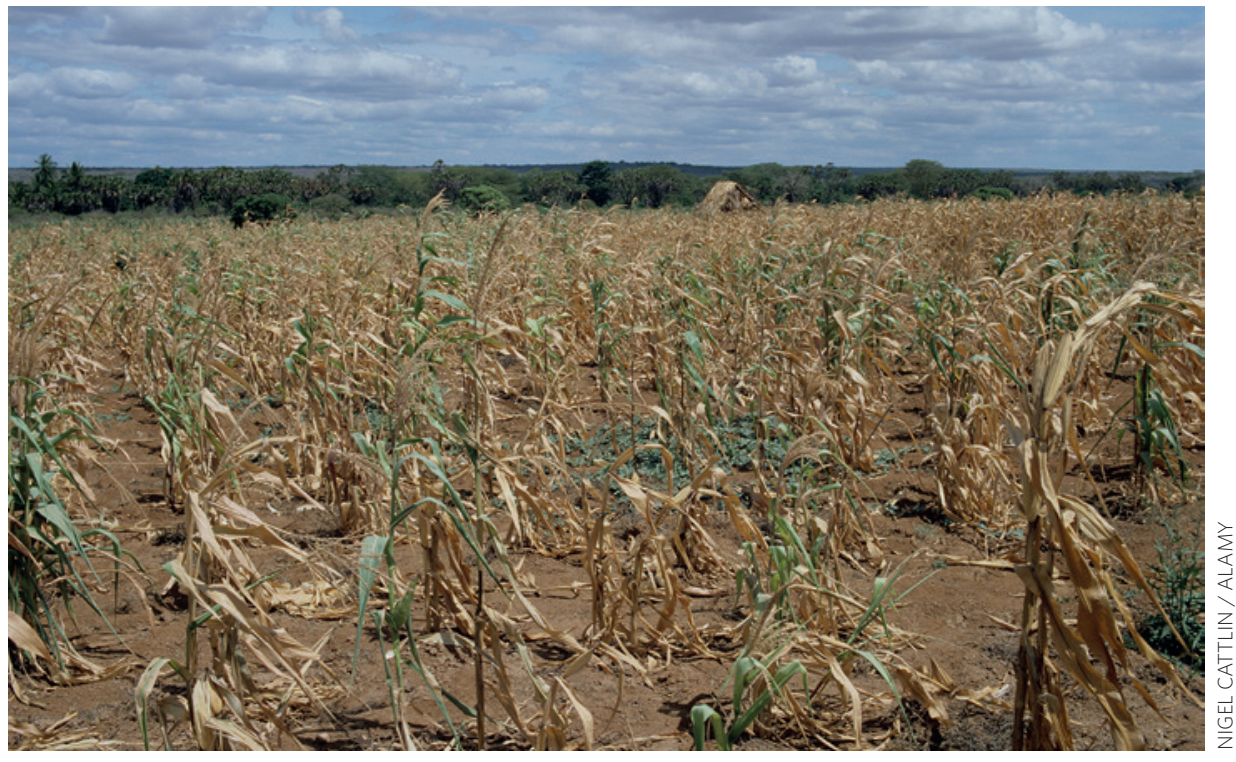

Figure 1 | Failed maize crop after severe drought in East Africa. Moore and Diaz use empirical estimates of the effect of temperature shocks on economic growth to show that the impact of warming on poor countries could be much higher than previously estimated, with severe consequences to the welfare of affected populations.

importance. Earlier studies have shown that SCC projections are particularly sensitive to the weight given to the welfare of future generations (as captured by the discount rate), the damage function specification, and to the treatment of uncertainty, especially regarding the possibility of catastrophic events $^{5-7}$. The main challenge is that for most of the above parameters, there is either no agreement among scientists or a lack of an empirical foundation. The damage function is notoriously difficult to estimate, as empirical data for global warming conditions higher than current ones are not available. Despite this, the damage functions used in IAMs are surprisingly similar between models, with almost all of them assuming that global warming does not affect economic growth, but only current economic output.

Moore and $\mathrm{Diaz}^{2}$ showed how the picture can change if warming does affect economic growth. The impact of such an assumption is mainly reflected in the long-term welfare effects. Assuming that climate change only affects economic output implies that there are no, or hardly any, permanent effects of warming. After all, the growth rate of the economy is not affected. If warming affected economic growth, there would be permanent effects on the economy. Intuitively, a permanent effect of warming on the economy makes sense: destruction of ecosystems and deaths from weather extremes will probably have a long-term effect ${ }^{8}$.

The authors are not alone in analysing the effect of warming on economic growth ${ }^{8,9}$. Their contribution, however, is the use of empirical estimates of the impact of temperature shocks on the economy ${ }^{10}$ to calibrate the damage function. Their newly derived damage function hardly changes the picture for rich countries, but the effect 
on poor countries is alarming (Fig. 1).

Without any climate policy, the impact of climate change on poor countries' economies would be a $40 \%$ income reduction by the end of the century, compared with a $12 \%$ income reduction according to the original damage function.

What does this mean for the SCC? With the original damage function, the estimated SCC was US $\$ 33$, which is of the same order of magnitude as the value currently used by the US government ${ }^{1}$. The authors find that the new damage function increases the SCC to a whopping US\$220. Using such a value would have a major impact in evaluations of projects that involve a change in $\mathrm{CO}_{2}$ emissions.

So how certain are we about the new projections? Not very, judging by the sensitivity analyses. The SCC estimate by Moore and Diaz is particularly sensitive to: uncertainties in the underlying data about the relationship between temperature shocks and economic growth; assumptions about how well society can adapt to warming; and the long-term resilience to global warming. The last of these factors is the most interesting, as it has the largest impact on SCC estimates.
In fact, the SCC could even be lower than the one obtained with the original damage function if resilience strongly increases with economic growth.

The sensitivity of the SCC estimate to the long-term resilience of economies to global warming leads us to the crucial question here: why are the negative impacts of warming so much higher in poor countries? Is it because on average poor countries have a hotter climate than rich countries and therefore are more vulnerable to even higher temperatures? Or is it simply because they are poor and therefore less able to adapt? If the former, using a (much) higher value for the SCC and stronger climate action might very well be warranted. If the latter, strong policies to curb $\mathrm{CO}_{2}$ emissions, which will lead to significant costs thereby slowing economic growth, may not be. Of course, rapid economic growth could increase the probability of catastrophic events, but current data on temperature shocks and economic growth cannot inform us about that.

Whilst a number of questions still need to be answered before policy decisions can be made, Moore and Diaz clearly show that historical data about the effects of temperature shocks on economic growth point to a much higher negative welfare impact of climate change on poor economies than previously thought - a result that calls for increased attention to the most vulnerable nations in the world

Andries Hof is at PBL Netherlands Environmental Assessment Agency, A. van Leeuwenhoeklaan 9, 3721 MA Bilthoven, the Netherlands.

e-mail: andries.hof@pbl.nl

References

1. Interagency Working Group on Social Cost of Carbon Technical Update of the Social Cost of Carbon for Regulatory Impact Analysis Under Executive Order 12866 (US Government, 2013).

2. Moore, F. C. \& Diaz, D. B. Nature Clim. Change 5, 127-131 (2015)

3. Pindyck, R. S. J. Econ. Lit. 51, 860-872 (2013).

4. van den Bergh, J. C. J. M. Ecol. Econ. 48, 385-393 (2004).

5. Hof, A. F., den Elzen, M. G. J. \& van Vuuren, D. P. Glob. Environ. Change 18, 412-424 (2008).

6. Calel, R., Stainforth, D. A. \& Dietz, S. Climatic Change http://dx.doi.org/10.1007/s10584-013-0911-4 (2013).

7. Weitzman, M. L. J. Publ. Econ. Theory 14, 221-244 (2012).

8. Pindyck, R. S. J. Environ. Econ. Manage. 63, 289-303 (2012)

9. Moyer, E. J., Woolley, M. D., Glotter, M. J. \& Weisbach, D. A. Climate Impacts on Economic Growth as Drivers of Uncertainty in the Social Cost of Carbon Working Paper 13-02 (Center for Robust Decision Making on Climate and Energy Policy, 2013).

10. Dell, M., Jones, B. F. \& Olken, B. A. Am. Econ. J. Macroecon. $4,66-95$ (2012)

\section{Extreme La Niña events to increase}

How climate change will impact the natural phenomenon La Niña, the counterpart of El Niño, has been unclear. In spite of uncertainty, now a study shows a large model consensus for an increasing frequency of extreme La Niña events.

\section{Antonietta Capotondi}

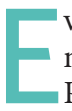
very two-to-seven years, cooler than normal conditions in the tropical Pacific Ocean, known as La Niña, drive atmospheric circulations that generate extreme weather events in many parts of the world, such as droughts, floods, and enhanced hurricane activity. These far-reaching impacts are particularly devastating for the strongest La Niña events. During the extreme 1998-1999 event the severity of droughts, floods, mudslides and hurricanes claimed thousands of people's lives, displaced millions, and caused dramatic economic losses in many parts of the world ${ }^{1}$. The physical mechanism of La Niña in the present climate is relatively well understood. However, there has been no consensus among climate models on how La Niña will change in a warming world ${ }^{2}$. Writing in Nature Climate Change, Wenju Cai and colleagues ${ }^{3}$ find a robust agreement among climate models concerning changes in La Niña - extreme events will become more frequent with global warming.

Usually, the eastern tropical Pacific is dry and cool, whereas the western Pacific is characterized by the warmest waters of the world ocean, accompanied by prodigious tropical rainfall (Fig. 1a). These average conditions are maintained by winds at the ocean surface which blow from east to west. During normal La Niña events surface easterly winds intensify, causing cooler and dryer conditions to develop in the central equatorial Pacific that lead to an increased temperature difference with the Maritime Continent, the area of the world that comprises parts of southeastern
Asia, Indonesia, and the Philippines. Tropical precipitation is shifted westwards, bringing enhanced rainfall over the Maritime Continent. These conditions are further intensified during extreme La Niña events: the central equatorial Pacific is much colder and drier, and rainfall is further enhanced in the far western Pacific (Fig. 1b).

How can extreme cold events become more frequent in a warmer climate? Climate change simulations show that the surface easterly winds, which are stronger during La Niña events and play a key role in their development, will on average weaken with global warming ${ }^{4}$, making the increased frequency of extreme La Niña episodes even more counterintuitive. According to Cai and colleagues there are, however, several inter-related factors that 